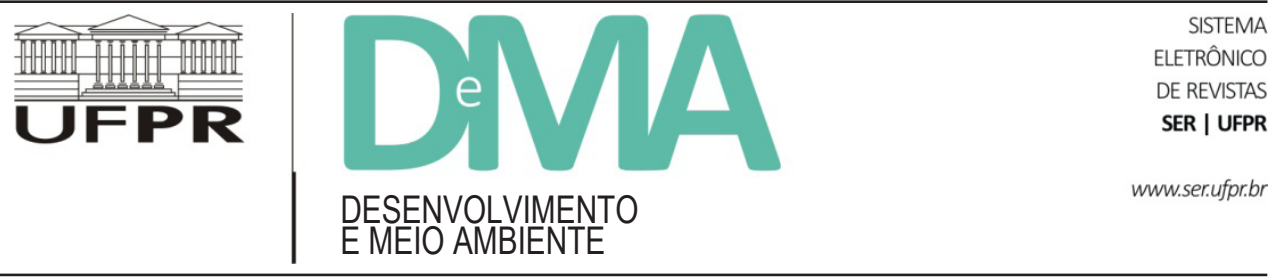

\title{
Bioindicadores ambientais: o que as diatomáceas dizem sobre o ambiente humano
}

\section{Environmental bioindicators: what diatoms say about the human environment}

\author{
Angela Maria da SILVA-LEHMKUHL ${ }^{1 *}$, Elton Augusto LEHMKUHL ${ }^{1}$, Denise de Campos BICUDO ${ }^{2}$ \\ ${ }^{1}$ Universidade Federal do Amazonas (UFAM), Manaus, AM, Brasil. \\ ${ }^{2}$ Núcleo de Ecologia, Instituto de Botânica, Secretaria do Meio Ambiente do Estado de São Paulo (SMA), São Paulo, SP, Brasil. \\ *E-mail de contato: angela_ecologia@yahoo.com.br
}

Artigo recebido em 22 de dezembro de 2018, versão final aceita em 20 de maio de 2019.

RESUMO: O ensaio objetiva refletir de que maneira as microalgas podem ser teoricamente concebidas e metodologicamente utilizadas como instrumento biotecnológico de sensoriamento responsável por aumentar capacidade de percepção/ação/cognição e comunicação acerca das dinâmicas antrópicas da natureza - considerando, em termos epistemológicos, que a razão científica se afasta do senso comum na medida em que gera experiências instrumentalizadas entre sujeito-objeto do conhecimento. Também ampliam e corrigem as experiências fenomenológicas limitadas às capacidades humanas circunscritas a regras neurofisiológicas e neuropsicológicas do corpo humano, ou às lógicas técnico-científicas de outras áreas do saber ligadas à política. Elas funcionam como biotecnologias capazes de fazer crescer e de corrigir a inteligência e a sensibilidade de sistemas teórico-metodológicos aplicados em planos de diagnóstico, monitoramento e ajustes ambientais. Enquanto biotecnologias, as microalgas funcionam como prolongamentos e potencializadores dos corpos e dos cérebros dos cientistas ou das comunidades acadêmicas reunidas no interior das Ciências do Ambiente. Por fim, considera alguns obstáculos epistemológicos que impedem a participação dos bioindicadores na esfera das políticas voltadas à gestão ambiental.

Palavras-chave: algas; bioindicação; gerenciamento ambiental; meio ambiente; recursos hídricos.

ABSTRACT: This study aims to reflect on how microalgae can theoretically be conceptualized and methodologically used as a biotechnological instrument of sensing to increase the capacity of perception/action/cognition and communication regarding the anthropic dynamics of nature - considering, in epistemological terms, that scientific reason departs from common sense insofar as it generates instrumentalized experiences between subject-object of knowledge. They also extend and correct phenomenological experiences limited to human capacities circumscribed to neurophysiological and neuropsychological rules of the human body or to the 
technical and scientific logics of other areas of knowledge linked to politics. Its work as biotechnologies capable of growing and correcting the intelligence and sensitivity of theoretical-methodological systems applied in plans for diagnosis, monitoring and environmental adjustments. As biotechnologies, microalgae work as extensions and potentiators of the bodies and brains of scientists or academic communities gathered within the Environmental Sciences. Finally, it considers some epistemological obstacles that prevent the participation of the bioindicators in the sphere of the policies directed to environmental management.

Keywords: algae; bioindication; environmental management; environment; water resources.

\section{Introdução}

O ensaio objetiva refletir de que maneira as microalgas podem ser teoricamente concebidas e metodologicamente utilizadas como instrumento biotecnológico de sensoriamento e informação racional responsável por aumentar abrangência objetiva de percepção/ação/cognição acerca das dinâmicas antrópicas da natureza, ao mesmo tempo em que contribui com o avanço científico em termos de inteligência coletiva (Lévy, 1996, p. 147-148) ou de conhecimento socializado (Bachelard, 1996, p. 297). Epistemologicamente, abordar as microalgas como objeto científico só faz sentido na medida em que os estudos as tornam instrumentos informacionais de percepção, reflexão e ação acerca de fenômenos ambientais; compreendendo, assim, a botânica no âmbito das ciências aplicadas e em suas relações interdisciplinares na área das Ciências Ambientais em sua tarefa de socializar e comunicar comportamentos da natureza.

As pesquisas nessa área circunscrita aos comportamentos das microalgas se justificam, portanto, na medida em que se comprova a função instrumental desses seres vivos à luz de teorias ecológicas que buscam estatisticamente explicar e traduzir os impactos qualitativos das ações antrópicas que transformam a natureza objetiva em ambiente humano. Trata-se de um desdobramento do projeto cibernético aplicado à biologia ou ao mundo dos viventes que consiste em "[...] encontrar-lhe um equivalente mecânico", transformando comportamentos orgânicos ou bioenergéticos em códigos matemáticos pautados em variações de pulsos elétricos binários ou computacionais (Merleau-Ponty, 2006, p. 260). Envolvendo uma relação informativa com a natureza é possível captar e compreender a dinâmica de entropia de um "microssistema" aquático sem contribuir sensivelmente com seu aumento; embora gere a entropia nos sistemas informacionais - bancos de dados - da ciência (Merleau-Ponty, 2006, p. 258-259).

O conjunto de instrumentos tecnológicos responsáveis por assimilar os comportamentos "performáticos" das microalgas consiste em uma máquina ou sistema mecânico capaz de traduzir matematicamente variações qualitativas da natureza. Segundo Merleau-Ponty (2006, p. 258): “As máquinas de informação são aparelhos para dar forma [matemática: aritmética, algébrica, geométrica] na medida em que são sensíveis à forma da excitação e respondem a essas formas". Como ciência aplicada à ecologia, a botânica das microalgas não tem a pretensão de abarcar uma compreensão ou contemplação absoluta da vida desses seres, mas sim extrair comportamentos codificáveis pelos sistemas da ciência e, assim, transformar esses códigos em linguagem social e politicamente comum. "Isso consiste, portanto, em restabelecer uma informação dada na coisa [...]. Uma máquina pode indicar automaticamente a lei de uma série de números ao eliminar as anomalias" (Merleau-Ponty, 2006, p. 261). 
Essas anomalias devem ser compreendidas como excessos de comportamento a serem lidos como números irracionais pelo computador estatístico; formas naturais não racionalizáveis em termos de formas geométricas - gráficas - produzidas pelo raciocínio algébrico da aritmética. "A partir daí, é fácil ver como a cibernética tende a tornar-se uma teoria do vivente e da linguagem" (Merleau-Ponty, 2006, p. 261). Sendo assim, é preciso levar em conta e conhecer o sujeito observador dos comportamentos das microalgas, que não se trata do sujeito humano; insensível e "analfabeto" aos comportamentos desses micro-organismos. A subjetividade humana do cientista é substituída pela subjetividade de uma máquina. Cientificamente, de acordo com o físico Readhead (1997, p. 37):

[...] 'observador' não significa um ser sensitivo (sentient being) - admitindo-se aí um elemento genuinamente subjetivo [um animal] -, mas é um termo usado simplesmente para se referir a um sistema de referência [de unidades de medidas e escalas], um sistema de réguas e relógios rigidamente fixados que é deixado em movimento relativo uniforme. Vamos chamar de relação relativa uma relação binária que é diferentemente valorada [na escala pautada em uma unidade de medida específica] em diferentes referenciais.

Em princípio, por um senso comum que se desdobrou sobre a "teoria da relatividade" de Einstein, considera-se que, ao estabelecer um observador, as microalgas " $[. .$.$] ficam relativizadas para diferentes$ observadores, de modo que tais relações perdem seu estatuto objetivo e dependem do ponto de vista do observador específico que atesta [afere e codifica] a relação em questão" (Reahead, 1997, p. 39). Contudo, sendo esse "observador" um sistema técnico capaz de traduzir qualidades naturais, insensíveis e incompreensíveis ao observador subjetivo humano, em quantidades numéricas sensíveis e compreensíveis ao observador subjetivo humano chamado cientista; considerando uma subjetividade socialmente treinada em termos profissionais, não sendo uma subjetividade leiga, comum ou geral.

Para Lévy (2001, p. 152), a ciência desenvolve-se pela digitalização da natureza. Os cientistas, portanto, passam a observar indiretamente a natureza. Bachelard (1996, p. 2917) diz que: “Assim, a precisão discursiva e social destrói as insuficiências intuitivas e pessoais. Quanto mais apurada é a medida, mais indireta ela é. A ciência do solitário é qualitativa. A ciência socializada é quantitativa". Desse modo, a ciência constrói uma realidade virtualmente digitalizada, numerizada, "[...] ligada à possibilidade de manter uma interação sensório-motora com o conteúdo de uma memória informática. Um explorador de realidade virtual não pode [...] esquecer que o universo sensorial no qual está mergulhado é calculado por um computador” (Lévy, 2001, p. 152). Os “[...] novos estítos de conhecimento se estabelecem sobre suportes informáticos $-[\ldots]$ principalmente [...] modelos numerizados de fenômenos físicos - que podem dar lugar a simulações interativas" (Lévy, 1996, p. 146).

No interior de uma comunidade científica específica, a "[...] coletividade constitui uma memória, instrumentos de percepção e análise comuns, sem, no entanto, convergir sobre um consenso, pois o debate é permanente. É por isso que falo de 'inteligência coletiva"” (Lévy, 2001, p. 153). Lévy (1996, p. 147-148) entende que a "[...] simulação sobre o suporte numérico é uma espécie de imaginação artificial". Os computadores não substituem pessoas ou cientistas; são, antes de tudo, “[...] amplificação das funções cognitivas das pessoas vidas $[\ldots]$. Essa $[\ldots]$ pode dizer respeito, também, às funções cognitivas de grupos, de equipes que trabalham juntas. [...] Há 
[...] cada vez mais instrumentos que servem para melhorar o trabalho em grupo".

Com efeito, estudar as microalgas significa investigar o ambiente de maneira indireta ou instrumental, de acordo com sistemas teóricos de referências socialmente controlados, responsáveis por tornarem os comportamentos das microalgas índices dos fenômenos ambientais antrópicos. Instrumentalizadas, as microalgas possibilitam o distanciamento do cientista de sua sensorialidade corpórea; bem como, formado socialmente, suspende sua fenomenologia centrada na subjetividade opinativa, na medida em que gera experiências teóricas e técnicas entre sujeitos, objeto e comunidade do conhecimento (Bachelard, 1999, p. 21). "Toda mensuração precisa é uma mensuração preparada. A ordem de precisão crescente é uma ordem de instrumentalização crescente; logo, de socialização crescente" (Bachelard, 1996, p. 296).

O instrumental constitui uma espécie de máquina de interface que compreende ou assimila a "língua comportamental" das microalgas e que traduz, "sem querer", para a linguagem da ciência: a matemática. Não é possível o contato direto e imediato entre humano e microalgas, senão mediante instrumentos técnicos. Com efeito, o ambiente para o cientista consiste em um "ambiente tecnológico", ou seja, representado por linguagens técnicas. Nas palavras de Merleau-Ponty (2006, p. 270), "[...] pôde-se dizer que a animalidade é o Logos do mundo sensível [...]. Têm-se a impressão de um corpo que manipula os objetos, da constituição da conduta do corpo que corresponde à situação". Em suma, o mundo orgânico implica "[...] uma realidade intermediária entre o mundo como existe para um [suposto] observador absoluto e um domínio puramente subjetivo". Ou seja, o observador científico não pode mais ser considerado absoluto ou universal, pois concerne a um domínio particularmente localizado; mas trata-se de uma subjetividade ou mente matemática que opera com um código numérico preciso.

Está em pauta uma reflexão epistemológica sobre a instrumentalização das microalgas para o contributo com o desenvolvimento tecnológico da razão científica em sua capacidade de tornar conhecidos fenômenos até então ocultos à fenomenologia da consciência humana. Isso acontece porque os aparatos sensoriais, motores e cognitivos dos humanos, centrados em sua fisiologia corporal, são insensíveis a certas alterações ambientais em relação às quais as microalgas são suscetíveis. $O$ corpo humano do cientista depende de equipamentos mais sensíveis que seus mecanismos e sistemas fisiológicos de percepção, ação e pensamento centrados em sua subjetividade corporal. "A ciência não é o conhecimento do objeto que eu toco, vejo, cheiro, degusto ou ouço; [...] ela recusa o corpo e olha as coisas com frieza e com espírito de geometria [aritmética e álgebra]" (Le Breton, 2016, p. 61).

As microalgas passam a se comunicar com um sistema de referências estatísticas. De um ponto de vista da técnica moderna, segundo Heidegger (2010, p. 20), a ciência faz com que a natureza funcione para as necessidades e desejos humanos. Semelhante à metáfora heideggeriana que diz estar o rio Reno instalado na usina e hidrelétrica e não ao contrário, as microalgas estão instaladas nos sistemas de sensoriamento ambiental. Contudo, a diferença entre ambos os exemplos está no fato de que a hidrelétrica transforma a energia materialmente; enquanto que os sistemas computacionais transformam a energia material em informação, contribuindo menos com a entropia dos sistemas físicos e biológicos. Para Merleau-Ponty (2006, p. 260), sobre a relação entre organismos vivos e as máquinas: "O transporte material é apenas um caso particular da comunicação, e a comunicação nada 
mais é do que a passagem efetiva de uma estrutura daqui para ali, de modo que há idealidade do movimento e realidade da comunicação".

Os computadores são máquinas informativas, por isso podem ampliar e corrigir as experiências fenomenológicas limitadas às capacidades humanas circunscritas às regras neurofisiológicas e neuropsicológicas do corpo humano enquanto instrumento de aferição/ação/cálculo/linguagem. As microalgas funcionam como biotecnologias capazes de fazer crescer e de corrigir a razão - inteligência - e a percepção - sensibilidade - de sistemas teórico-metodológicos aplicados em planos de diagnóstico, monitoramento e ajustes ambientais. Enquanto biotecnologias, as microalgas funcionam como prolongamentos e potencializadores dos corpos e dos cérebros dos cientistas ou das comunidades acadêmicas reunidas no interior das Ciências do Ambiente.

Assim, as microalgas podem ser consideradas um órgão "artificial" do corpo científico, de modo que elas o tornam sensível a comportamentos naturalmente imperceptíveis. Não perdendo de vista suas causas antrópicas, filosoficamente as microalgas oferecem a oportunidade de refletirmos sobre as inconsequências e irresponsabilidades do ser humano moderno, pois elas servem de ligação entre ação e resultado, permitindo que a humanidade veja a si própria refletida na matemática dos fenômenos ambientais e não mais atribuir às mudanças climáticas causas naturais. As microalgas como bioindicadoras de poluição aquática, por exemplo, podem contribuir com a antiga tarefa humana anunciada pelo Oráculo de Delfos, Grécia Antiga: “conhece-te a ti mesmo". Não obstante, a história da humanidade vem demonstrando que esse enunciado só pode ser cumprido mediante relações de alteridade em oposição a quaisquer ilusões psicológicas ou ideológicas de autonomia ou separação do "homem" em face da natureza e da sociedade; dominadas e exploradas.
Compreende-se que o humano não pode conhecer a si senão com a ajuda do outro. Esse outro, é necessário dizer, não se restringe a outro humano, a exemplo de psicólogos, psicanalistas, psiquiatras ou antropólogos, que cotidianamente ajudam pessoas a compreenderem suas atitudes sociais por meio de suas linguagens conceituais e metodológicas. Doravante, o desenvolvimento da consciência humana de si e do mundo sempre foi - cada vez mais - dependente dos sentidos, das ações e das inteligências dos outros seres. Para não prolongar uma sucessão de exemplos, bastam os casos mais significativos em que caçadores humanos "escutam" e "farejam" a partir da audição e do olfato do cachorro, ao mesmo tempo em que um galo substitui um despertador eletrônico durante as férias de uma família urbana passadas na zona rural.

Na Mongólia, caçadores valem-se dos olhos de águias e falcões para localizarem e capturarem seus alimentos vivos; o pescador utiliza uma minhoca no anzol como isca que simula a presa ou alimento natural do peixe. Todas essas relações são tecnológicas porque consistem em instrumentos que aumentam o poder do corpo humano de sentir, pensar, agir e comunicar em sua dimensão ambiental. Importante frisar que esses animais biotecnológicos não complementam ou corrigem apenas a sensibilidade e a motricidade humanas. Todos esses exemplos demonstram que os outros seres participam do aumento das capacidades cognitivas voltadas à sobrevivência de grupos culturalmente identificados, pois a depender das informações e dados captados por biotecnologia, as associações de ideias, as avaliações e os cálculos econômicos e políticos, as interpretações são passíveis de reformulação e de revisão no interior de sistemas simbólicos que organizam o mundo das experiências científicas.

Do mesmo modo que as apreensões e as expressões corporais humanas estão associadas 
aos sistemas teóricos de juízo racionais científicos ou fenomenológicos de um indivíduo, os animais também estão ligados aos rigorosos sistemas de análise e de síntese construídos por referenciais teórico-metodológicos acordados pelas comunidades acadêmicas institucionais. São instrumentos da racionalidade científica. Não são apenas os cães os amigos do "homem"; as microalgas também são.

Mas, para as relações biotecnológicas serem estabelecidas, o componente comunicacional é indispensável. Essa questão envolve os desafios da tradução e da transferibilidade de dados em sistemas com codificações diferentes, quando se trata de dois seres diferentes, de dois idiomas humanos distintos ou de unidades de medidas e escalas numéricas diversas. Outrossim, ao passo que as biotecnologias ambientais não se limitam às conexões puramente sensório-motrizes, os cientistas esforçam-se para aplicar o juízo correto sobre uma sensação/ação dada. Decifrar os comportamentos das microalgas é tão desafiador quanto um neurologista tentando entender o que significa cada um dos impulsos bioelétricos do cérebro representados em gráfico computacional.

A função biotecnológica das microalgas depende de intensos trabalhos para descobrir seus códigos e ao máximo diminuir as chances de "mal-entendidos". Ainda mais quando as mensagens cifradas das microalgas dizem ou revelam aspectos negativos da vida humana. Aliás, as pesquisas apontam que as microalgas não vêm "dizendo" "boas" coisas a respeito dos humanos. Existem, portanto, relações de identidade entre humanos e microalgas. Essas relações são de difícil apreensão porque não se trata de uma identificação por semelhança anatômica, tal como podemos dizer acerca dos primatas. Também não se trata de um vínculo por semelhanças comportamentais, aos moldes das analogias entre as cidades e os formigueiros e as colmeias (WWF-Brasil, 2004, p. 12).
A conexão humano-microalga implica cifras que se comportam como índices ou sintomas físico-químicos, afastando ainda mais as possibilidades fenomenológicas de diagnósticos da qualidade da água e do ambiente ao mesmo tempo em que insere a consciência desse elo no âmbito restrito dos conhecimentos e técnicas científicos. Em outras palavras, a consciência ambiental promovida pelas interações entre humanos e microalgas se deve ao intenso processo de racionalização instrumental que as Ciências Ambientais vêm passando nos últimos anos a partir dos diálogos entre ciência, tecnologia e sociedades. Não obstante, a perspectiva ambiental fornecida pela leitura dos dados produzidos pelas microalgas consiste em um ponto de vista exclusivamente possibilitado pelas técnicas aplicadas, de modo que, sem essas, tal ambiente permanece velado às sensações, ações e racionalizações humanas. Como foi dito acima, "[...] a animalidade é o Logos do mundo sensível [...]" (Merleau-Ponty, 2006, p. 260).

Da mesma forma que os seres humanos mudam quando a zona de conforto é pressionada por fatores externos, as microalgas também alteram a estrutura de sua comunidade quando sensíveis a alterações do meio, induzidas pelo homem. Protocolos e técnicas adotadas para monitorar as alterações na estrutura da comunidade de microalgas envolvem conhecimentos e técnicas taxonômicos e ecológicos das espécies. $\mathrm{O}$ fato das alterações não serem apreensíveis fora do horizonte do desenvolvimento da ciência e tecnologia, entende-se o ambiente revelado como fenômeno estritamente técnico, cuja linguagem é compreensível para a subjetividade teórica e metodologicamente socialmente treinada do cientista; uma intersubjetividade controlada pela comunidade científica, sendo que compreensão está reservada a quem participa do grupo. "Convém notar, aliás, que toda doutrina da 
objetividade acaba sujeitando o conhecimento do objeto ao controle de outrem. [...] ciência moderna trabalha com materiais experimentais e com quadros lógicos socializados há muito, e, por conseguinte, já controlados" (Bachelard, 1996, p. 296).

A bioindicação é uma frente de pesquisa na área de ecologia aquática que estuda como os organismos aquáticos respondem às alterações na qualidade da água. As respostas incluem o desaparecimento de espécies que não toleram as mudanças do meio juntamente ao aumento da densidade de espécies que levam vantagens competitivas ou a mudança na composição e organização das espécies após alterações nas condições ambientais. A ecologia, reconhecida desde meados de 1900 como um campo da ciência, é de interesse prático para racionalmente mediar relações da sociedade humana com a natureza, especialmente a água, de modo a configurar outro ambiente. A interdisciplinaridade envolvendo ciência, aspectos sociais, econômicos e da natureza integram o conhecimento profilático para manutenção da saúde do homem, de seu bem-estar e do ambiente em que ele vive (Odum $\&$ Barret, 2007).

Nesse contexto, temos como objetivos abordar o uso de bioindicadores, especificamente das microalgas diatomáceas, como ferramenta de avaliação da qualidade da água, bem como fazer uma interlocução entre as atividades humanas e as respostas desses microrganismos. Ainda, descreveremos as rotinas de coleta, preparação do material, identificação das espécies, bem como as dificuldades enfrentadas para consolidar o uso desses microrganismos pelas agências responsáveis pelo monitoramento e gerenciamento dos corpos d'água brasileiros. O texto está estruturado em subtópicos, primeiramente introduzindo conceitos gerais sobre níveis de organização ecológica e aspectos sobre algas e bioindicadores. A partir dessa contextua- lização básica, passaremos a discorrer sobre as técnicas utilizadas e as avaliações realizadas. Por fim, realizaremos algumas considerações sobre os obstáculos políticos para a adoção das técnicas bioindicadoras de poluição pelos gestores sociais.

\section{Os efeitos ambientais da modernidade tecnológica: a questão da água}

Os avanços tecnológicos estão na base da consciência ambiental e das ações desdobradas a partir dela. O conceito de ambiente transforma-se na proporção em que as tecnologias se desenvolvem. Não obstante, quaisquer tecnologias responsáveis por permitir que a consciência apreenda um novo dado oriundo da natureza, também poderá sugerir uma revisão das atitudes ambientais. Contudo, o progresso tecnológico, até o momento, também tem contribuído para um velamento ou redução da consciência ambiental. As tecnologias também são capazes de tornar cientistas e sociedades insensíveis e incompreensíveis diante da natureza. Sendo assim, na sequência será tratado o panorama atual da sociedade moderna em relação às transformações ambientais geradas pelos avanços tecnológicos, que por sua vez possibilitaram o desenvolvimento e crescimento da vida urbana em grandes cidades.

$\mathrm{O}$ aumento da população mundial tem levado a grandes mudanças na disponibilidade de recursos naturais básicos para a vida. Como fato emblemático, no século XX, enquanto a população aumentou quatro vezes, ou três vezes desde 1950, o uso da água aumentou desproporcionalmente 7,7 vezes, uma vez que esse consumo aumenta de acordo com a urbanização e a renda da população, os quais alteram seu padrão de uso e consumo (UNDP, 2006). Segundo Porto-Gonçalves (2012, p. 153): "No Canadá, entre 1972 e 1991, enquanto a população cresceu 3\%, o 
consumo de água cresceu $80 \%$, segundo a ONU". Conforme Petrella (apud Porto-Gonçalves, 2012, p. 153), "[...] um cidadão alemão consome em média nove vezes mais água doce que um cidadão na Índia”. Associado à urbanização, aumentos do consumo de água "[...] exigem captação de água a distâncias cada vez maiores $[\ldots]$ ".

Porto-Gonçalves (2012, p. 151 e 155) detalha que a agricultura mundial responde por $70 \%$ do consumo da água de superfície, da qual a indústria consome $20 \%$ e o uso doméstico $10 \%$. No Brasil, respectivamente, a água superficial apresenta os seguintes números: $61 \%, 18 \%$ e $21 \%$. Referente às águas subterrâneas, o setor agrícola utiliza 38\%, a indústria $25 \%$ e o consumo doméstico é de $37 \%$. "Nos anos 1990, na América do Norte, 50\% de todo o consumo dos habitantes foi obtido em águas subterrâneas, segundo a ONU [...]. Na China também é cada vez maior a proporção de águas captadas [...]" (Porto-Gonçalves, 2012, p. 157). O grande consumo de águas subterrâneas provoca a salinização. "Em Madras, na Índia, a captação [...] subterrânea levou a um rebaixamento de tal ordem do lençol freático que as águas salgadas avançaram pelo subsolo cerca de 10 quilômetros continente adentro [...]".

Concernente às águas de superfície, como veremos à frente com mais detalhes, em que se desenvolvem a maioria dos estudos sobre microalgas como bioindicadores de qualidade da água, os grandes reservatórios para abastecimento e/ou geração de energia elétrica implicam as mudanças mais drásticas no uso e no destino do recurso hidrológico. Com base em dados da ONU, Porto-Gonçalves (2012, p. 154) informa que no último meio século, entre 40 e 80 milhões de habitantes, na maioria camponesa e indígena, sofreram com inundações voltadas para formação de diques e barragens. "Dos 227 maiores rios do mundo, $60 \%$ foram barrados por algum dique nesse mesmo período e, ainda em
1998, estavam sendo construídos [...] 349 diques com mais de 60 metros de altura em diferentes países [...] com grande impacto sócio ambiental". Com essas transformações, a qualidade das águas superficiais também compõe e ilustra a natureza complexa e de longo prazo das interações do homem com o seu ambiente. Problemas de poluição advindos de efluentes domésticos, agrícolas e/ou industriais tornaram-se um dos grandes desafios para os recursos hídricos, principalmente em países industrializados e em desenvolvimento. Atividades humanas têm introduzido ao meio ambiente substâncias não conhecidas (xenobióticos e radionucleotídeos), com múltiplas ações sobre a tolerância dos organismos (Markert et al., 2003). Assim, cada vez mais é necessário que o meio ambiente e os serviços ecossistêmicos sejam reconhecidos e aceitos como uma extensão fisiológica do homem, sendo fundamentais para seu bem-estar, e que pequenas mudanças no ambiente podem causar desequilíbrios homeostáticos no homem.

Historicamente, a civilização coincide com o uso do fogo e de outros instrumentos como meios de modificar o ambiente para se adequar às suas necessidades. Há uma íntima relação do indivíduo com a natureza, a qual foi se perdendo com o avanço e domínio das tecnologias e, atualmente, mesmo aspectos fisiológicos básicos dependentes do ambiente (respirar, disponibilidade de água e alimento) parecem ser esquecidos pelo homem (Odum \& Barret, 2007). A sobrevivência na Terra depende de ciclos naturais básicos, e a saúde humana depende da capacidade de a sociedade enxergar os efeitos da natureza e de seus componentes bióticos e abióticos como parte inerente à sua sobrevivência (Rigotto, 2003).

Embora as águas de água doce sejam irrefutáveis fontes de sobrevivência e de constituírem um fator controlador e estratégico para o desenvolvi- 
mento das atividades humanas (contexto de recursos hídricos), é crescente a situação de rarefação desses recursos, e ações mitigadoras para impedir a degradação desse recurso e melhorar o uso racional dos corpos d'água são urgentes e necessárias (Magalhães Júnior, 2011). Particularmente, trataremos neste texto a relação causa-efeito das atividades humanas sobre a comunidade de algas microscópicas nos ecossistemas aquáticos, descrevendo de que maneira as pesquisas com bioindicação podem auxiliar no entendimento dos efeitos das ações humanas sobre a qualidade das águas a partir das respostas da comunidade de microalgas.

\section{Contextualização ecológica}

A ecologia, primeiramente definida por Ernst Haeckel, em 1866, como "a ciência capaz de compreender a relação do organismo com o seu ambiente", particularmente no que tange à distribuição das espécies, hoje pode ser definida como "o estudo científico da distribuição e abundância de organismos e das interações que determinam sua distribuição e abundância" (Townsend et al., 2010).

A abordagem ecológica pode ser feita conforme escalas, que podem ser temporais, espaciais e/ou biológicas. Dentro da escala biológica, ocupam-se três níveis: (1) de organismos individuais, tendo em vista como esses são afetados pelo ambiente e como eles interferem no ambiente; (2) de populações, que consistem em indivíduos da mesma espécie, visando ao estudo da presença, ausência, abundância e das flutuações no número de espécies de interesse; e (3) de comunidades, que consiste em todas as populações presentes em uma determinada área de interesse e suas organizações em composição e abundância (Townsend et al., 2010; Odum, 2001).
Uma maneira de se estudar a organização das comunidades em ecologia é inicialmente conhecer sua estrutura, a qual pode ser descrita pela quantidade de espécies (riqueza), pela quantidade de indivíduos de cada espécie, diversidade de espécies, a qual contempla a riqueza, o número de indivíduos e a uniformidade em sua distribuição. Fatores como variáveis químicas e físicas do ambiente, interações entre as espécies, posição geográfica, grau de interferência no ambiente e eventos aleatórios influenciam na estrutura das comunidades.

Nesse contexto, as comunidades são compostas por espécies que possuem respostas distintas às alterações das condições ambientais, e aqui diferenciaremos três categorias: espécies tolerantes, resistentes e sensíveis. A tolerância das espécies/ comunidades diz respeito à capacidade que esses organismos possuem de se adaptar fisiologicamente às condições desfavoráveis e de ter sucesso na perpetuação da espécie. Organismos resistentes são geneticamente capazes de suportar um "stress" ambiental. A sensibilidade de organismos e comunidades diz respeito à vulnerabilidade das espécies às mudanças bióticas e abióticas. Espécies com alta sensibilidade podem diminuir em densidade ou até mesmo desaparecer do ambiente transformado, enquanto que espécies com baixa sensibilidade às mudanças conseguem se manter em condições adversas (Markert et al., 2003).

A resposta dos organismos frente a alterações ambientais sempre foi objeto de estudo de ecólogos e observadores da natureza. Organismos ou comunidades de organismos, cuja existência está fortemente associada com condições químicas e físicas específicas, são excelentes bioindicadores ambientais (Suter, 2001). E alterações em número, diversidade, morfologia, fisiologia e comportamental desses organismos fornecem indícios de que as condições do ambiente foram modificadas 
para além dos limites toleráveis pelas espécies ou comunidades (Gerhardt, 2002).

$\mathrm{O}$ uso de bioindicadores ambientais surge como uma ferramenta chamada bioindicação em programas de monitoramento biológico. O biomonitoramento é realizado de uma maneira intermitente, de maneira a fornecer um banco de dados em escala temporal, e a partir dessas informações é possível conhecer e determinar variações nos padrões das estruturas das comunidades (Hellawell, 1991). E dependendo do tipo de alterações, é possível inferir o tipo de distúrbio ambiental que está ocorrendo.

Tendo estabelecido os conceitos necessários para entender a importância dos bioindicadores, agora é necessário escolher qual grupo de organismos é mais adequado para utilizar como bioindicador e para responder às nossas questões. Conhecer a biologia do organismo ou comunidade é o primeiro passo para estabelecermos as técnicas e metodologia para alcançarmos os objetivos do trabalho. Aqui nos ateremos ao biomonitoramento em ecossistemas aquáticos, utilizando microalgas diatomáceas como bioindicadores.

É importante ressaltar que a bioindicação não exclui o uso de instrumentos e de análises laboratoriais que medem pontualmente as condições físicas e químicas do ambiente. Essas informações são correlacionadas com as respostas da comunidade biológica, de forma a dar subsídio para diagnosticar a integridade e saúde ambiental, cenário impossível de se obter somente com as medidas de natureza pontual. Uma das grandes vantagens do uso de bioindicadores é que eles fornecem informações integradas sobre condições ambientais em escala temporal, ou seja, acumulam informações ao longo do tempo (Suter, 2001; Markert et al., 2003).

Podemos diferenciar cinco abordagens para o uso da bioindicação como ferramentas de avaliação da qualidade das águas: (1) a primeira refere-se à toxicidade dos componentes presentes na água. Essa medida pode ser realizada com bioensaios, nos quais os organismos ficam expostos a ambientes que recebem efluentes domésticos ou industriais e, em seguida, observa-se os efeitos danosos a esses organismos; (2) bioconcentração e bioacumulação, que avaliam a exposição dos organismos aos poluentes e seus efeitos ao longo da cadeia trófica. Os resultados desses estudos são úteis para a avaliação dos perigos dos compostos liberados indiscriminadamente para o meio ambiente, principalmente se esses compostos são lipossolúveis e não são rapidamente transformados ao longo dos processos biológicos, podendo acumular-se nos tecidos dos animais; (3) o uso da bioindicação como integrante de monitoramento biológico, compondo uma base de dados que pode ser constantemente consultada para comparar a composição biológica de diferentes locais e para avaliar padrões da comunidade nos diferentes ambientes; (4) bioindicação como auxiliar na determinação de compostos químicos conhecidos; (5) avaliação dos impactos passados e recentes que as mais diversas atividades humanas podem causar nos ecossistemas aquáticos (Norris \& Norris, 1995; Markert et al., 2003).

Para os objetivos deste trabalho, focaremos as abordagens que utilizam a bioindicação para classificação do estado trófico do meio e para avaliação de impactos passados e recentes em ambientes aquáticos continentais.

\section{Como reconhecer as microalgas diatomáceas}

As algas são um grupo de organismos aquáticos altamente diversos, clorofilados, fotossintetizantes, com estruturas vegetativas simples, com órgãos de reprodução compostos de tecidos com 
células estéreis, sem sistema vascular. Podem ser unicelulares, coloniais, filamentosos, pseudofilamentosos, parenquimatosos, pseudoparenquimatosos ou cenocíticos. São amplamente distribuídas, ocorrem em todos os tipos de ambientes aquáticos e até mesmo em superfícies úmidas associadas com plantas, fungos e solo (Bicudo \& Menezes, 2017; Sheat \& Wehr, 2003).

Dentre os grupos de microalgas, as diatomáceas são abundantes, cosmopolitas e podem ser encontradas em quase todos os tipos de habitat. Estima-se que existam cerca de 12 mil espécies de diatomáceas descritas para a ciência (Mann \& Vanormelingen, 2013). As diatomáceas são facilmente reconhecidas por apresentar uma parede celular impregnada de sílica, compostas de duas valvas encaixadas, as quais formam a frústula. De forma mais simplificada, as diatomáceas são classificadas dentro de duas ordens artificiais: a ordem Centrales (cêntricas), que abrange os indivíduos com simetria radial, e a ordem Pennales (penadas), que inclui os representantes de simetria bilateral (Figura 1) (Julius \& Theriot, 2010).

A forma, o tamanho e as ornamentações dessa parede de sílica são características que permitem a identificação e diferenciação dos gêneros e, dentro destes, das espécies (Smol \& Stoermer, 2010).

Quanto ao hábito, as algas diatomáceas podem ser classificadas em planctônicas e perifíticas. As planctônicas estão livremente suspensas na coluna d'água, enquanto que as perifíticas estão aderidas a algum tipo de substrato submersos em regiões

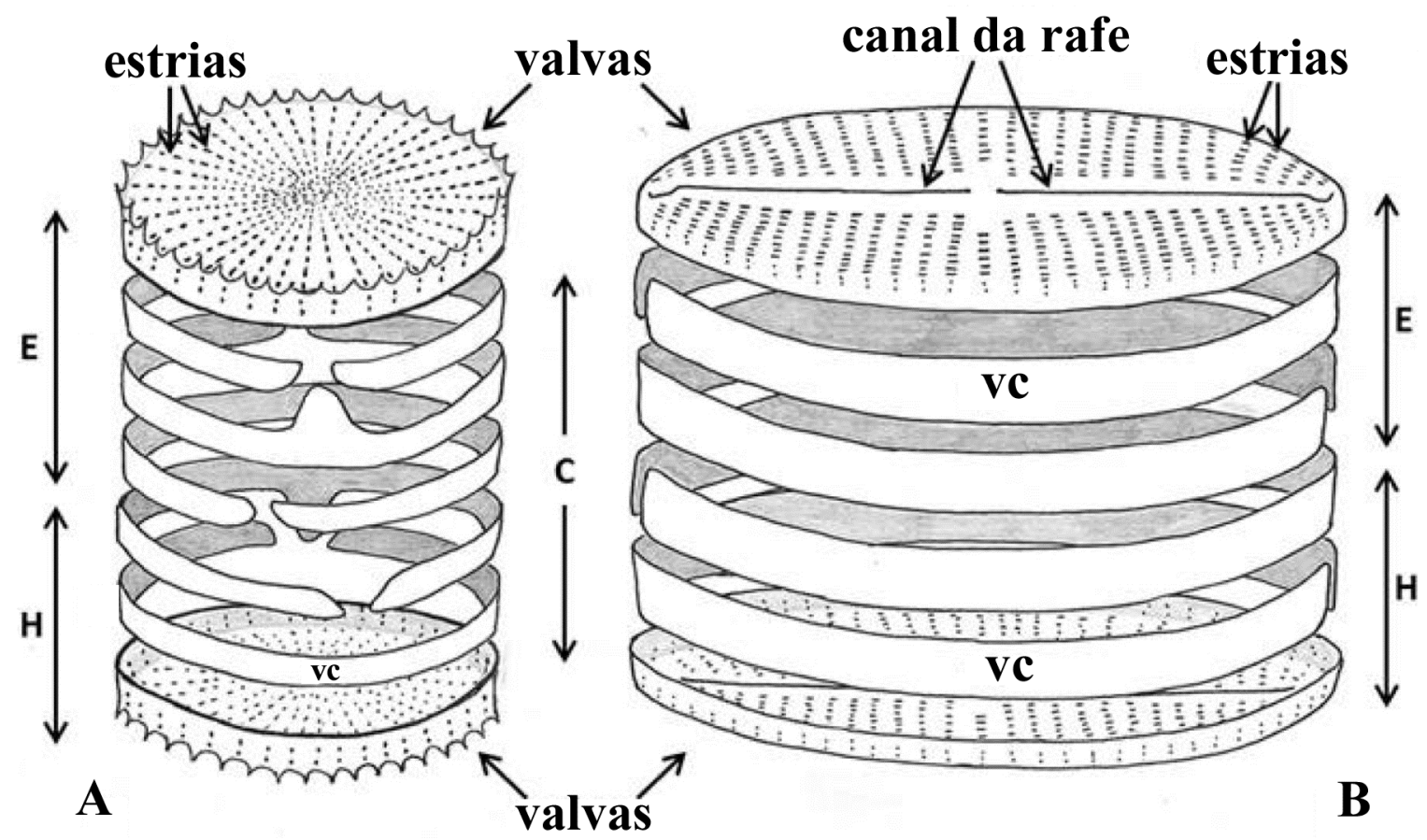

FIGURA 1 - Esquema das valvas das diatomáceas, mostrando suas divisões e ornamentações. A - Representação de uma diatomácea cêntrica. B - Representação de uma diatomácea penada. Epivalva, (E), Hipovalva $(H)$, banda do cíngulo mais próxima da valva é denomidada de valvocópula (vc), conjunto de bandas do cíngulo (c).

FONTE: Cox (2014, fig. 1). 


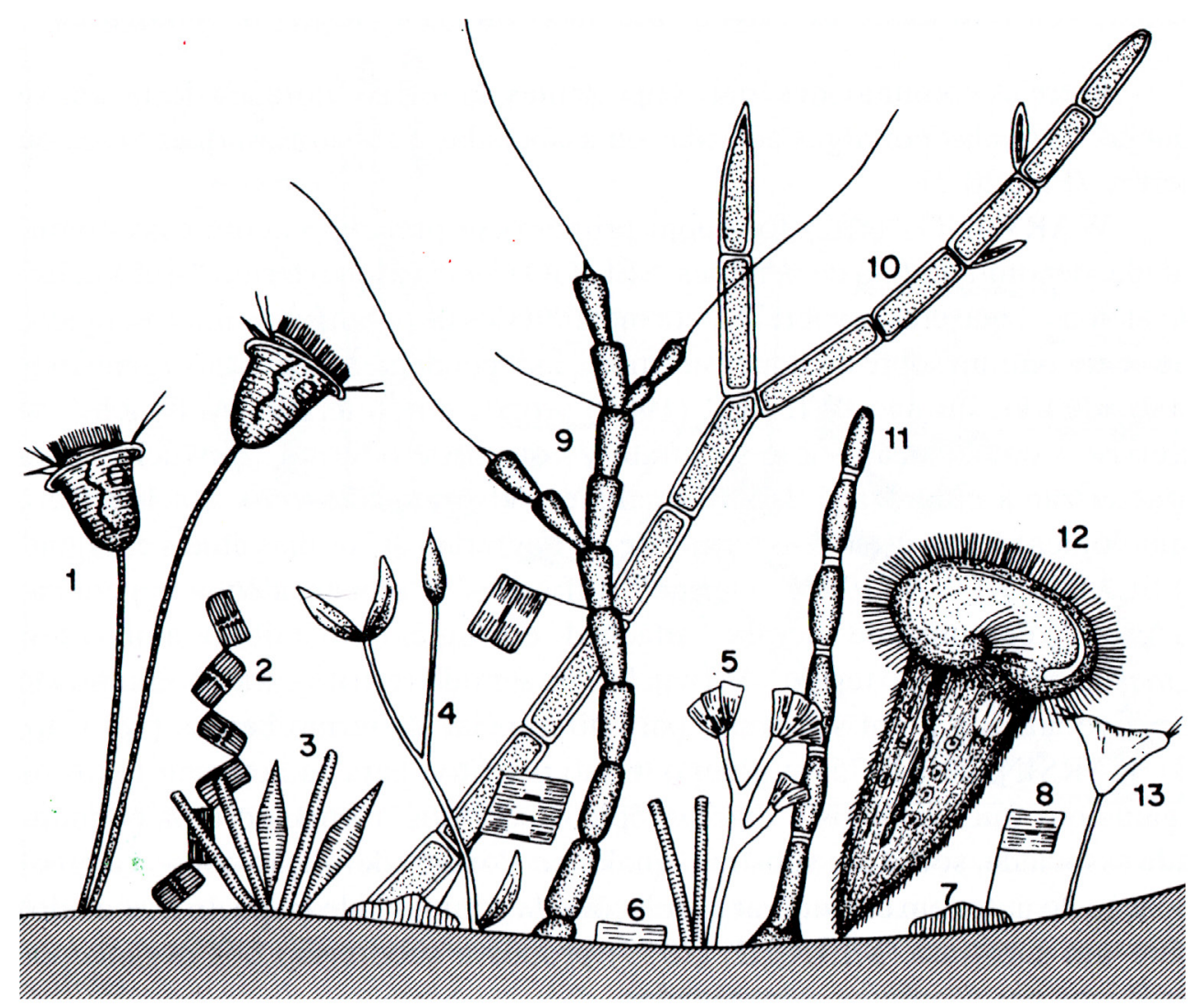

FIGURA 2 - Representação da comunidade perifítica sobre folha de macrófita aquática. (1 e 12) protozoários; (2-8) microalgas diatomáceas; (9-11) microalgas clorofíceas; (13) acineto. FONTE: Segundo Kalbe (1985) retirado de Esteves (1998, fig. 20.3).

iluminadas (zona eufótica) e as associadas a substratos do fundo são denominadas bentônicas e também nomeadas de acordo com o tipo de substrato (Wetzel, 1983; Stevenson et al., 1996). As algas diatomáceas perifíticas colonizam o substrato pela liberação de uma matriz mucilaginosa com capacidade de adesão aos substratos (Bicudo \& Menezes, 2017) (Figura 2).

De acordo com a natureza do substrato, as algas diatomáceas bentônicas recebem denominações específicas: se aderidas em plantas, são epifíticas; em animais, são epizóicas; episâmicas, aderidas a grãos de areias; epipélicas, sobre o sedimento; se aderidas a rochas, são epilíticas; e sobre madeira, epidêndricas; ainda, quando frouxamente aderidas ao substrato, ou à matriz mucilaginosa da camada perifítica, são denominadas metafíticas (Burliga \& Schwarzbold, 2013) (Figura 3).

Parece desafiador pensar em como esse grupo de microalgas, não perceptíveis a olho nu, pode ser relevante para a escala do ecossistema e para o bem-estar do ser humano. A diferença está de 


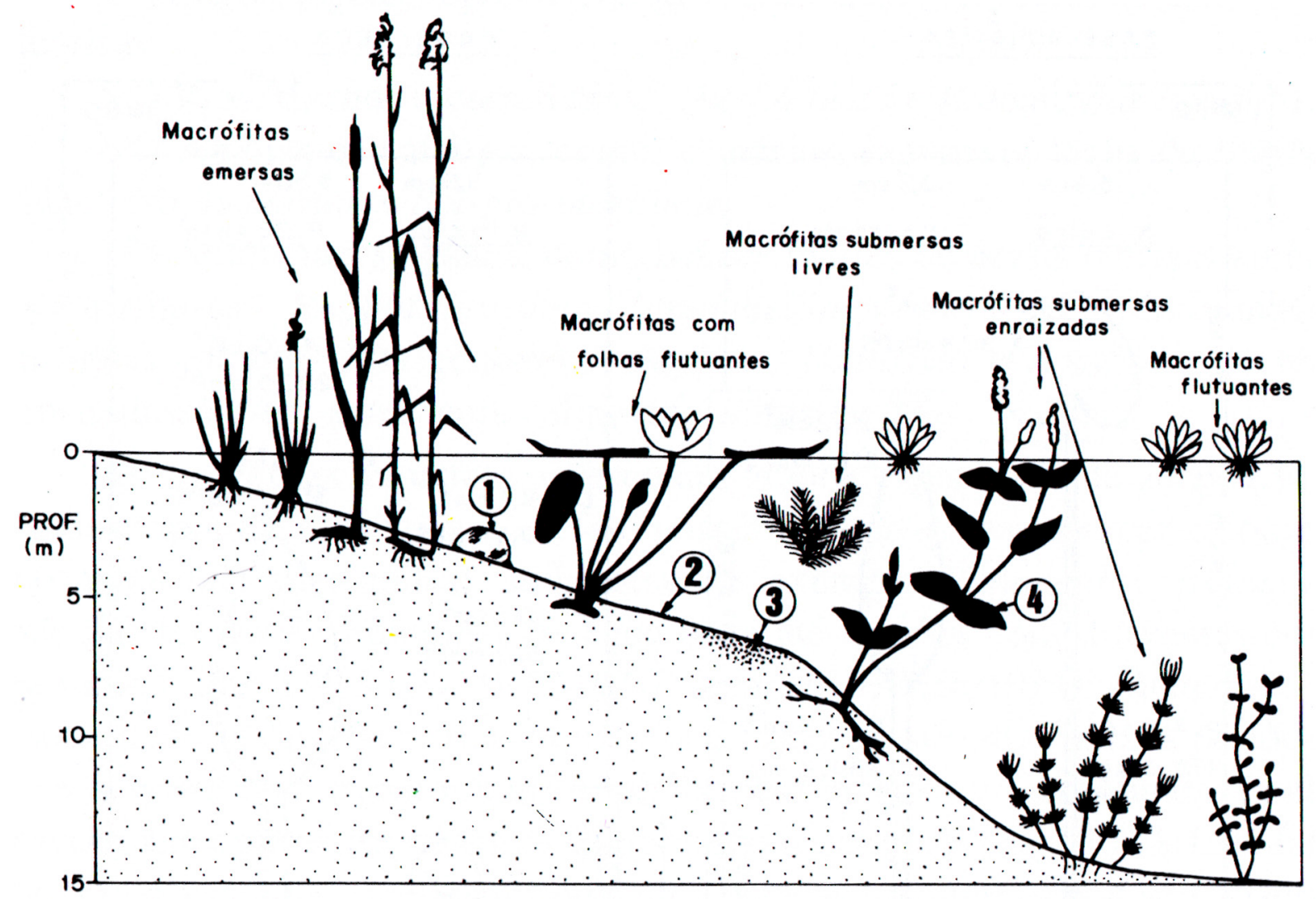

FIGURA 3 - Representação das comunidades bentônicas de acordo com a natureza do substrato: (1) epilítica; (2) epipélica; (3) episâmica; (4) epifítica.

FONTE: Esteves (1998, fig. 20.2).

fato na escala, no que é visível aos olhos e de sua importância direta para o homem. Por exemplo, é até de fácil compreensão o entendimento do homem sobre a importância direta dos vegetais superiores relacionados à alimentação, como batatas, arroz, feijão (Smol \& Stoermer, 2010), no entanto, é quase impossível imaginar as relações de causa-efeito quando uma espécie de diatomácea relacionada a uma determinada condição ambiental deixa de existir em um ecossistema aquático. Somente uma inteligência racionalmente coletiva e científica, além de sustentada por instrumentos e protocolos, pode considerar esse fenômeno como fato real e existente; que em termos sociais é possível dizer, um fato político.

Um maior entendimento sobre a presença de algumas espécies de diatomáceas e outros fenômenos foi possível com a evolução do microscópio de luz, o que também permitiu avançar sobre o conhecimento da citologia e em teorias evolutivas sobre as diatomáceas (Smol \& Stoermer, 2010). Após o período da Segunda Guerra Mundial, as novidades 
tecnológicas permitiram melhorias na microscopia eletrônica e nos computadores, as quais impulsionaram os estudos sobre a estrutura das diatomáceas e aplicação estatística multivariada para relacionar a comunidade de diatomáceas com fatores ambientais (Smol \& Stoermer, 2010; Birks, 2010).

Smol \& Stoermer (2010) sistematizam o estudo das diatomáceas em três eras: primeira, entre 1830 e 1900, denominada "era da exploração", a qual foi marcada pela identificação e descrições de novos táxons, descobertas sobre o ciclo de vida e a fisiologia das espécies, e um breve conhecimento sobre a distribuição geográfica e temporal desses organismos. Um dos marcos de desse período foi o conceito de "espécies indicadoras". A segunda era (1900-1970), nomeada "era da sistematização", tinha como objetivo criar sistemas que tornassem as diversas informações mais gerenciáveis, chamados de sistemas e espectros, nos quais as diatomáceas foram ordenadas de acordo com suas preferências ecológicas. A era vigente, ou "era da objetificação", é marcada pelo avanço das ferramentas computacionais, tornando possível determinar quantitativamente e com precisão mensurável quais as variáveis que mais influenciam na ocorrência e no crescimento das espécies.

Diferenciar as eras pelas fases de compreensão racionalmente instrumental do papel das diatomáceas para a ciência e sociedade é mais que de natureza didática, é uma necessidade do homem de se organizar no tempo e espaço a partir das técnicas e conhecimentos que domina. Na verdade, nenhuma dessas eras se estagnaram, pois o conhecimento gerado se acumula e se transforma, e novas espécies continuam sendo descobertas. Estudos sobre o ciclo de vida e fisiologia continuam a avançar e o uso das espécies como indicadores ambientais continua sendo realizado em âmbito mundial, porém com ferramentas e metodologia cada vez mais avançadas; de modo que também se pode falar em representações ambientais segundo modelos teóricos mais avançados.

\section{Diatomáceas como bioindicadores}

As diatomáceas destacam-se como bons bioindicadores ambientais, auxiliando no monitoramento da qualidade ambiental dos ecossistemas aquáticos, inferindo sobre os processos de alteração ambiental no presente, no passado e no futuro. As principais características que as tornam bons indicadores ambientais são por apresentarem: (1) ampla distribuição geográfica, e podem ser encontradas nos mais diversos tipos de ambientes aquáticos (águas continentais, marinhas, lagos, rios); (2) elevada riqueza de espécies com diferentes exigências ecológicas, de modo que alterações podem levar tanto ao desaparecimento de táxons sensíveis, como ao desenvolvimento daqueles que são favorecidos com algumas mudanças, bem como à permanência de táxons tolerantes; (3) curto ciclo de vida, uma a algumas divisões por dia, de forma a reagirem quase instantaneamente às alterações do meio, sendo consideradas indicadoras de resposta rápida; (4) envoltório celular de sílica $\left(\mathrm{S}_{\mathrm{i}} \mathrm{O}_{2}\right)$, que contribui com a preservação das valvas no sedimento, resistindo à decomposição por bactérias, dissolução química e ruptura física, permitindo sua identificação correta mesmo estando depositada por longa data no sedimento. Essa característica auxilia em trabalhos de reconstrução ambiental e climática; (5) grande quantidade de informações sobre a ecologia de diversas espécies, o que é imprescindível para o sucesso do monitoramento (Bennion, 1995; Sayer et al., 1999; Lobo et al., 2002; Harding et al., 2005; Smol, 2008; Beyene et al., 2009; Kociolek, 2010; Bennion et al., 2011). 


\section{Metodologia e técnicas}

Os corpos d'água prestam serviços essenciais para a manutenção da vida, além de serem norteadores de atividades humanas. Assim, monitorar a qualidade ecológica desses ambientes é fundamental para evitar colapsos ambientais, que incorrem em perdas de espécies importantes para que os ecossistemas continuem exercendo seu papel no meio ambiente. O reconhecimento dos recursos hídricos como sistemas complexos e interconectados, resultantes de variados graus de respostas às fontes externas (naturais ou artificiais), e que variam em função das múltiplas atividades (sociais e econômicas), é fundamental para que o gerenciamento se dê em nível de ecossistema integrado (bacia hidrográfica, usos e demandas) e preditivo (Tundisi, 2007).

Para nortear o uso das diatomáceas como ferramenta no monitoramento, primeiramente se define qual a comunidade de diatomáceas será utilizada e pontos estratégicos para captar alterações no ambiente. Diatomáceas perifíticas e do sedimento superficial são comunidades de interesse para obter esse tipo de informação. As perifíticas destacam-se por ficarem presas ao substrato e em contato direto com as condições do ambiente, de modo que qualquer alteração na qualidade da água, a comunidade vai responder facilmente.

As espécies encontradas no sedimento superficial vêm ganhando notoriedade: por integrarem amostras espaciais e temporais dos eventos que se acumularam no passado recente, bem como conter táxons de organismos provenientes de todos os hábitos do ecossistema (plâncton e perifíton), sua avaliação permite verificar o efeito ainda mais integrado das alterações dos ecossistemas, inviável de ser obtido com o uso de comunidades vivas (Bennion, 1995).
Os sedimentos superficiais também vêm sendo amplamente estudados visando elaborar redes de calibração com diatomáceas para construção de modelos inferenciais, a exemplo do modelo DI-PT (diatomáceas-fósforo). A aplicação desses modelos inferenciais em reconstruções paleolimnológicas permite inferir as concentrações pretéritas do fósforo na água, ou de outra variável de interesse, sendo de grande interesse para o gerenciamento ambiental, uma vez que fornece as condições basais dos ecossistemas lacustres, subsidiando metas de recuperação (Bennion et al., 2004; Smol, 2008; Bennion \& Simpson, 2011; Davidson \& Jeppsen, 2013). O uso das diatomáceas de sedimentos (superficiais e cores) também vem sendo incorporado a programas de gerenciamento, a exemplo do WFD-European Council Water Framework Directive (European Union, 2000).

\subsection{Variáveis limnológicas abióticas em campo e em laboratório}

Em campo devemos fazer medidas de alguns parâmetros físicos e químicos da água importantes para relacionar com a comunidade de diatomáceas. $\mathrm{O}$ avanço das tecnologias possibilitou o desenvolvimento de equipamentos multiparamétricos portáteis, compostos de sensores específicos para medir mais de uma variável (temperatura, $\mathrm{pH}$, condutividade e oxigênio dissolvido, profundidade), o qual diminuiu o número de equipamentos levados a campo e otimizou o tempo e espaço para as coletas.

Outra medida importante e simples de ser obtida com o uso de um disco de Secchi é a transparência da coluna d'água. O disco é formado por faixas brancas e pretas, amarrado a uma corda com marcações métricas; a medida dá-se pelo desaparecimento do disco na coluna d'água. Esses equipa- 
mentos são de simples manuseio, necessitando de conhecimentos operacionais básicos.

No entanto, para medidas de nutrientes da água e outros componentes químicos impossíveis de serem obtidos em campo, é necessário coletar um volume suficiente de água para executar as técnicas analíticas em laboratório. As amostras de água devem ser condicionadas em frascos adequados para os objetivos das amostras e etiquetados com informações da amostra. É imprescindível transportar os frascos em caixas térmicas. O ideal é que as análises sejam realizadas no mesmo dia da coleta, pois muitos compostos podem ser voláteis e não serem identificados se houver demora nas análises.

Para as análises laboratoriais, é necessário conhecimento técnico e operacional especializado, a fim de evitar acidentes com compostos químicos. Conhecimento analítico para executar com precisão os protocolos adotados para quantificação dos nutrientes da água também é fundamental. Basicamente os métodos utilizados para variáveis limnológicas abióticas seguem os seguintes protocolos: alcalinidade (Golterman \& Clymo, 1969), nitrato e nitrito (Mackereth et al., 1978), nitrogênio amoniacal (Solorzano, 1969), fósforo solúvel reativo e fósforo total dissolvido (Strickland \& Parsons, 1960), nitrogênio total e fósforo total (Valderrama, 1981) e sílica solúvel reativa (Golterman et al., 1978).

O conhecimento das variáveis limnológicas é fundamental para relacionar com a estrutura e organização das diatomáceas, para que então a leitura integrada da qualidade ecológica do ambiente seja analisada.

\subsection{Coleta das diatomáceas}

Para ir a campo coletar o material é importante estar munido de frascos de volume conhecidos, devidamente identificados com as informações do local, data e comunidade que está sendo amostrada. Independentemente do substrato amostrado, é fundamental conhecer a área que as diatomáceas estão sendo retiradas e o volume que esse material raspado vai ser diluído. Essas informações são imprescindíveis para estimar a abundância de cada espécie em uma unidade de medida (indivíduos por $\mathrm{ml}$ de amostra, por exemplo).

Por se tratar de uma amostra viva, os processos metabólicos dos organismos continuam ocorrendo dentro daquele frasco, por isso é fundamental o uso de um fixador, que consiste em uma solução que paralisa as atividades metabólicas de todos os organismos, permitindo que a amostra seja preservada para análises posteriores. A recomendação é escolher uma solução fixadora de baixo custo, fácil obtenção e que preserve o máximo a aparência das algas. Para as diatomáceas é comum fixar as amostras com solução aquosa de formalina a 4\% (cerca de quatro gotas dessa solução para cada $100 \mathrm{ml}$ de amostra) (Bicudo \& Menezes, 2017).

\subsection{Preparação das amostras, identificação e contagem das diatomáceas}

Para conseguirmos visualizar as características morfológicas para identificação das espécies de diatomáceas, é necessário oxidar as amostras. Essa técnica consiste na retirada de toda a matéria orgânica da amostra, deixando somente as frústulas das diatomáceas para serem visualizadas em microscopia de luz com capacidade de aumento de $1000 \mathrm{X}$.

Para a execução das técnicas e protocolos para confecção das lâminas contendo diatomáceas até a etapa de visualização em microscopia, é necessário o conhecimento básico operacional dos equipamentos e soluções químicas utilizadas. O método 
de oxidação de diatomáceas mais utilizado é o descrito por Battarbee (1986), que utiliza peróxido de hidrogênio e ácido clorídrico $10 \%$. As lâminas permanentes precisam ser montadas, utilizando um meio de inclusão com índice de refração que possibilite visualizar as frústulas das diatomáceas. O meio de inclusão mais utilizado é o Naphrax ${ }^{\circledR}$ com índice de refração de 1.73 .

A identificação das diatomáceas exige treinamento e capacitação das pessoas envolvidas, para que elas consigam reconhecer e diferenciar gêneros e espécies. Cursos e workshops periódicos com especialistas em diatomáceas auxiliam a comunidade interessada em aprender como identificar as espécies de diatomáceas.

Com as lâminas de microscopia prontas, segue para a etapa de identificação e contagem de indivíduos de cada espécie. Essas informações são compiladas em tabelas contendo o ponto de coleta, as espécies e quantidades de cada espécie encontrada naquele ponto. Isso se repete para todos os ambientes amostrados e para coletas periódicas. A partir dessas tabelas se conhece estrutura e organização da comunidade de diatomáceas ao longo do tempo.

Se as condições ambientais permanecerem constantes, a composição de espécies não será alterada significativamente. No entanto, se o padrão de abundância e frequência de algumas espécies se alterar significativamente, é sinal de que eventos de alguma grandeza ocorreram no ecossistema. A partir dessas observações, é possível retornar ao banco de dados e identificar o ponto onde as alterações em estrutura de comunidade estão ocorrendo e relacionar com as variáveis limnológicas coletadas. O relatório das análises deve ser encaminhado aos gestores para que eles possam averiguar o local e identificar quais os fatores de "stress" ambiental.

\section{Considerações finais: obstáculos epistemológicos para inserção das diatomáceas na vida da política ambiental}

No Brasil, a legislação não obriga as agências que monitoram os ecossistemas aquáticos a realizarem análises da comunidade de diatomáceas, o que já é rotina em alguns países da Europa, onde as agências responsáveis pelo gerenciamento dos corpos d'água contratam laboratórios especializados em diatomáceas para realizarem as identificações e emitirem relatórios ambientais. É certo que as etapas que constituem o sucesso da bioindicação empregam uma rede de colaboradores de diferentes níveis do conhecimento, exigem recursos humanos com conhecimentos operacionais básicos e especializados e conhecimento científico para analisar e interpretar os resultados. Além da necessidade de infraestrutura física e recursos financeiros para operacionalizar todas as etapas. No entanto, os resultados levantados fornecem informações úteis e aplicáveis em diversas áreas do conhecimento.

Os resultados podem ser utilizados para tomadas de decisões na escolha de áreas prioritárias para conservação ambiental, para recuperação, também para avaliar os impactos ambientais causados pelas atividades humanas em torno da bacia. Ainda, alertam sobre o uso do solo, despejos de esgotos não tratados por empresas dos mais diversos setores e inferem sobre o estado de resiliência ambiental. São infinitas as informações que as comunidades de diatomáceas podem fornecer ao homem e auxiliá-lo a tomar medidas menos prejudiciais ao meio ambiente.

No entanto, trata-se de um trabalho que demanda uma escala de tempo maior por parte de todos os envolvidos para se obter respostas úteis. 
O tempo metodológico gasto acaba contrapondo-se à demanda exigida por respostas rápidas pelos tomadores de decisões e, talvez por isso, o uso de bioindicadores ainda seja motivo de resistência para gestores e instituições que monitoram a qualidade das águas brasileiras. A necessidade de respostas rápidas vai de encontro ao avanço tecnológico.

Atualmente, as pessoas são movidas por meios de informação de rápido acesso e que sejam quase que instantaneamente assimiladas pelas vias cognitivas. Um enorme disparate se comparado com o conhecimento científico. E essa transferência de comportamento ao longo dos níveis hierárquicos da sociedade, chegando àqueles que monitoram o gerenciamento ambiental, acaba trazendo consequências desastrosas e ineficientes para o meio ambiente e prejuízos imensuráveis ao homem.

Com efeito, supomos que embora o reconhecimento do uso das microalgas como eficientes bioindicadores das alterações ambientais seja cientificamente comprovado, sensibilizar órgãos governamentais responsáveis por gerir os recursos hídricos a utilizá-las como ferramenta complementar no monitoramento da qualidade dos corpos d'água, bem como sensibilizar a sociedade como um todo, é um desafio que os ecólogos aquáticos enfrentam; justamente porque a visada ambiental aqui proposta é absolutamente dependente da racionalidade tecno-científica, não sendo, portanto, significativa para a sensibilidade e a racionalidade fenomenológica desde que ocorrem as negociações políticas e sociais na esfera da gestão pública. Devido a essa diferença de experiências epistemológicas, em que os instrumentos políticos são distintos - em suas objetividades, validades, confiabilidades e categorias - daqueles da botânica, está fora de questão exigir, por princípio, que biólogos e gestores tenham a mesma consciência ou representação ambiental, já que essas estão condicionadas ou alienadas à mediação e racionalidade tecno-científica de seus respectivos instrumentos.

Por isso, compreende-se que as dificuldades de sensibilização podem estar relacionadas a diversos fatores, como a falta de percepção do indivíduo em reconhecer um corpo d'água como parte integrante de seu ambiente, até questões didáticas, educacionais e econômicas ligadas à formação cidadã sustentadas na formação científica. Sem isso, os biólogos continuarão a melhor compreenderem - "conversarem com" - as microalgas, ao mesmo tempo em que os discursos políticos permanecerão verdadeiros enunciados metafísicos aos seus ouvidos; sendo a recíproca verdadeira. O princípio da noção ambiental dos animais, racionalmente limitada a um tipo de reação ao que é perceptível aos seus sentidos e às suas potencialidades motrizes de ação, também se aplica aos seres humanos. Isso quer dizer que do ponto de vista de um observador, animal, humano ou máquina, a representação ambiental se altera de acordo com as transformações técnicas que sofrem ao longo da filo e da ontogênese.

Considerando que a assimilação das microalgas aos modelos teórico-metodológicos das Ciências Ambientais envolve um modo de evolução tecno-científica da humanidade, é possível defender a hipótese de que esse tipo de biotecnologia amplia nossa consciência sensorial, motora, cognitiva e informativa do ambiente; ao ponto de constatarmos que não é possível pensar o ambiente hoje sem conhecermos e refletirmos sobre as técnicas disponíveis para o exercício de nossa razão no âmbito das Ciências Ambientais e seus compromissos com conceitos e categorias como desenvolvimento e sustentabilidade. É nesse sentido que compreendemos a "racionalidade ambiental".

As microalgas, apenas visíveis ao microscópio ótico em aumento mínimo de 100 vezes, passam despercebidas ou mesmo desconhecidas para o 
ambiente humano, limitado aos seus instrumentos biológicos e lógicos próprios de outras ciências como a política ou o direito. Esse fato faz com que informações "não visíveis" sejam perdidas ou mesmo não processadas pelo homem e, portanto, permaneçam como fenômenos apolíticos. Ou seja, certas degradações ambientais perceptíveis aos corpos das microalgas, então percebidas pelo olhar tecno-científico do biólogo (ecólogo, engenheiro, cientista etc. ambientais), não podem ascender à esfera da política como reais e fatídicos, justamente porque os políticos, administradores e gestores são técnica e cientificamente insensíveis aos fenômenos vistos pelas lentes das Ciências Ambientais.

Não se trata de uma insensibilidade moral, mas sim epistemológica. Não obstante, urge à esfera da república incorporar ou assimilar as técnicas e os conhecimentos científicos para participarem dos planos de governo. É nesses termos a compreen- são de que a ciência pode sensibilizar a política, bem como a ela oferecer mecanismos racionais de ação, então dependentes de técnicas ambientais específicas. Com base nessas reflexões, é necessário compreender que qualquer mudança positiva na representação acerca de uma dimensão da experiência humana que ultrapasse os limites do corpo e que chamamos de ambiente depende do domínio político de técnicas disponíveis.

\section{Agradecimentos}

À Fundação de Amparo à Pesquisa do Estado do Amazonas (Fapeam) pela bolsa de doutorado à primeira autora (Fapeam Edital n. ${ }^{\circ}$ 003/2015 RH-Interiorização) e ao segundo autor (Fapeam Edital n. ${ }^{\circ}$ 010/2015 RH-Interiorização).

\section{Referências}

Bachelard, G. A formação do espirito científico: contribuição para uma psicanálise do conhecimento. Tradução de Esteia dos Santos Abreu. Rio de Janeiro: Contraponto, 1996.

Bachelard, G. O materialismo racional. Tradução de João Gama. Lisboa: Edições 70, 1999.

Battarbee, R. W. Diatoms analysis. In: Berglund, B. E. (Ed.). Handbook of Holocene Palaeohydrology. New York: John Wiley \& Sons, 1986. p. 527-570.

Bennion, H. Surface-sediment diatom assemblages in shallow, artificial, enriched ponds and implications for reconstructing trophic status. Diatom Research, 10(1), 1-19, 1995. doi: 10.1080/0269249x.1995.9705326

Bennion, H. et al. Assessing eutrophication and reference conditions for Scottish freshwater lochs using subfossil diatoms. Journal of Applied Ecology, 41, 124-138, 2004. doi: 10.1111/j.1365-2664.2004.00874.x
Bennion, H. et al. Defining reference conditions and restoration targets for lake ecosystems using palaeolimnology: a synthesis. Journal of Paleolimnology, 45, 533-544, 2011. doi: 10.1007/s10933-010-9419-3

Bennion, H.; Simpson, G. L. The use of diatom records to establish reference conditions for UK lakes subject to eutrophication. Journal of Paleolimnology, 45, 469-488, 2011. doi: 10.1007/s10933-010-9422-8

Beyene, A. et al. Comparative study of diatoms and macroinvertebrates as indicators of severe water pollution: Case study of the Kebena and Akaki rivers in Addis Ababa, Ethiopia. Ecological Indicators, 9, 381-392, 2009. doi: 10.1016/j.ecolind.2008.05.001

Bicudo, C. E. M.; Menezes, M. Gêneros de algas continentais do Brasil. Chave para identificação e descrições. 3. ed. São Carlos: Editora RIMA, 2017. 
Birks, H. J. B. Numerical methods for the analysis of diatom assemblage data. In: The diatoms: applications for the environmental and earth sciences. 2 ed. New York: Cambridge University Press, 2010.

Burliga, A. L.; Schwarzbold, A. Perifíton: diversidade taxonômica e morfológica. In: Ecologia e Perifiton. São Carlos: Rima, 2013.

Cox, E. J. Diatom identification in the face of changing species concepts and evidence of phenotypic plasticity. Journal of Micropalaeontology, first published 21 de agosto de 2014. doi: 10.1144/jmpaleo2014-014

Davidson, T. A.; Jeppsen, E. The role of paleolimnology in assessing eutrophication and its impact on lakes. Journal of Paleolimnology, 49, 391-410, 2013. doi: 10.1007/ s10933-012-9651-0

Esteves, F. A. Fundamentos de Limnologia. 2. ed. Rio de Janeiro: Interciência, 1998.

European Union. Directive 2000/60/EC of the European Parliament and of the Council of 23 October 2000 establishing a framework for Community action in the field of water policy. Official Journal of the European Communities, 327, p. 1-73, 2000.

Gerhardt, A. Bioindicator species and their use in biomonitoring. In: Environmental Monitoring I. Encyclopedia of life support systems (EOLSS), Developed under the Auspices of the UNESCO. Oxford: Eolss Publishers, 2002.

Golterman, H. L.; Clymo, R. S. Methods for chemical analysis of freshwaters. Oxford and Edinburg: Blackwell Scientific Publications. International Biological Programme. 1969.

Golterman, H. L. et al. Methods for physical and chemical analisys offresh waters. 2. ed. Oxford: Blackwell Scientific Publications. International Biological Program, 1978.

Harding, W. R. et al. The relevance of diatoms for water quality assessment in South Africa: A position paper. Water SA, 31(1), 41-46, 2005. doi: 10.4314/wsa.v31i1.5119

Heidegger, M. A questão da técnica. In: Heidegger, M. Ensaios e conferências. Tradução de Emmanuel Carneiro Leão et al. 6. ed. Petrópolis, RJ: Vozes, 2010. p. 11-38. (Coleção Pensamento Humano)

Hellawell, J. M. Development of a rationale for monitoring. In: Goldsmith, F. B. (Ed.). Monitoring for Conservation and Ecology. London: Chapman \& Hall, 1991. p. 1-14.
Julius, M. L.; Theriot, E. C. The diatoms: a primer. In: Smol, J. P.; Stoermer, E. F. (Eds.). The diatoms: applications for the environmental and earth sciences. 2 ed. New York: Cambridge University Press, 2010.

Kalbe, L. Leben in Wassertropfen. Jena: Urania-Verlag Leipzig, 1985.

Kociolek, J. P. Microscopic in size: macroscopic in impact. Diatom-human interactions. In: Dubinsky, Z.; Seckbach, J. (Eds.). All flesh is grass, cellular origin, life in extreme habitats and astrobiology 16. Springer Science+Business Media B.V., 2010.

Le Breton, D. Antropologia dos sentidos. Tradução de Francisco Morais. Petrópolis, RJ: Vozes, 2016.

Lévy, P. A inteligência coletiva, por uma antropologia do ciberespaço. In: Pessis-Pasternak, G. (Org.). A ciência: deus ou diabo? Tradução de Edgar de Assis Carvalho et al. São Paulo: Editora UNESP, 2001. p. 145-154.

Lévy, P. A inteligência e seus novos instrumentos. In: Scheps, R. (Org.). O império das técnicas. Tradução de Maria Lúcia Pereira. Campinas, SP: Papirus, 1996. (Coleção Papirus Ciência).

Lobo, E. A. et al. Utilização das algas diatomáceas epilíticas como indicadoras da qualidade da água em rios e arroios da Região Hidrográfica de Guaíba, RS, Brasil. Santa Cruz do Sul: Edunisc. 2002.

Mackereth, F. J. H. et al. Water analysis: some revised methods for limnologists. Cumbria: Freshwater Biological; Kendall: Ed. Wilson, Son Ltda, 1978.

Magalhães Junior, A. P. Indicadores ambientais e recursos hídricos: realidade e perspectivas para o Brasil a partir da experiência francesa. 3. ed. Rio de Janeiro: Editora Bertrand Brasil, 2011.

Mann, D. G.; Vanormelingen P. An inordinate fondness? the number, distributions, and origins of diatom species. Journal of Eukaryotic Microbiology, 60, 414-420, 2013. doi: 10.1111/jeu.12047

Markert, B. A. et al. Definitions, strategies and principles for bioindication/biomonitoring of the environment. In: Markert, B. A.; Breure, A. M.; Zechmeister, H. G. (Eds.). Bioindicators \& Biomonitors: principles, concepts and applications. Oxford: Elsevier, 2003. p. 3-42. 
Merleau-Ponty, M. A Natureza: notas de curso no College de France. Tradução de Álvaro Cabral. São Paulo: Martins Fontes, 2006. (Tópicos)

Norris, R. H.; Norris, K. R. The need for biological assessment of water quality: Australian perspective. Australian Journal of Ecology, 20, 1-6, 1995. doi: 10.1111/j.14429993.1995.tb00516.x

Odum, E. P. Fundamentos de Ecologia. 6. ed. Lisboa: Fundação Calouste Gulbenkian, 2001.

Odum, E. P.; Barret, G. W. Fundamentos de Ecologia. 5. ed. São Paulo: Thomsom Learning, 2007.

Porto-Gonçalves, C. W. O desafio ambiental. $3^{\text {a }}$ ed. Rio de Janeiro: Record, 2012. (Os porquês da desordem mundial. Mestres explicam a globalização).

Readhead, M. Da fisica à metafísica. Tradução de Valter Alnis Bezerra. Campinas, SP: Papirus, 1997. (Coleção Papirus Ciência)

Rigotto, R. M. Saúde Ambiental \& saúde dos trabalhadores: uma aproximação promissora entre o verde e o vermelho. Revista Brasileira de Epidemiologia, 6(4), p. 388-404, 2003. Disponível em: https://www.scielosp.org/pdf/rbepid/2003. v6n4/388-404/pt

Sayer, C. et al. Biodiversity changes in a shallow lake ecosystem: a multi-proxy palaeolimnological analysis. Journal of Biogeography, 26, 97-114, 1999. doi: 10.1111/j.13652699.1999.00298.x

Sheat, R. G.; Wehr, J. D. Introduction to the freshwater algae. In: Wehr, J. D.; Sheat, R. G.; Kociolek, J. P. (Eds.). Freshwater algae of North America: ecology and classification. London: Elsevier, 2003.

Smol, J. P. Pollution of lakes and rivers: a paleoenvironmental perspective. 2. ed. Oxford: Blackwell Publishing. 2008.
Smol, J. P.; Stoermer, E. F. Applications and use of diatoms: prologue. In: Smol, J. P.; Stoermer, E. F. (Eds.). The diatoms: applications for the environmental and earth sciences. 2 ed. New York: Cambridge University Press, 2010.

Solorzano, L. Determination of ammonia in natural waters by the phenolhypochlorite method. Limnology and Oceanography, 14, 799-801, 1969. doi: 10.4319/lo.1969.14.5.0799

Stevenson, R. J. et al. Algae ecology: freshwater benthic ecosystems. California: Academic Press, 1996.

Strickland, J. D.; Parsons, T. R. A manual of sea water analysis. Bull. Fish. Res. Bel. Can., 125, 1960.

Suter, G. W. Applicability of indicator monitoring to ecological risk assessment. Ecological Indicators, 1, 101-112, 2001. doi: 10.1016/S1470-160X(01)00011-5

Townsend, C. R. et al. Fundamentos em Ecologia. Porto Alegre, RS: Editora Artmed, 3. ed., 2010.

Tundisi, G. J. Gerenciamento integrado de bacias hidrográficas e reservatórios: estudo de caso e perspectivas. In: Nogueira, M. G.; Henry, R.; Jorcin, A. (Orgs.). Ecologia de Reservatórios: impactos potenciais, ações de manejo e sistemas em cascata. 2. ed. São Carlos, SP: Editora Rima, 2007.

UNDP - United Nations Development Programme. Human Development Report 2006, beyond scarcity: power, poverty and the global crisis. New York: Palgrave Macmillan. 2006.

Valderrama, G. C. The simultaneous analysis of total nitrogen and total phosphorus. Natural waters. Mar. Chem., 10, 109-122, 1981.

Wetzel, R. G. Periphyton of Freshwater Ecosystems. The Netherlands: Dr. W. Junk Publishers, 1983.

WWF-Brasil. Redes: uma introdução às dinâmicas da conectividade e da auto-organização. 2. ed. Texto: Cássio Marinho. Brasília: WWF-Brasil, 2004. 